\title{
GWO-based MPPT controller for grid connected Solid oxide fuel cell with high step up DC-DC converter
}

\author{
Sudhakiran Ponnuru ${ }^{1}$, R. Ashok Kumar ${ }^{2}$, N.M.Jothi Swaroopan ${ }^{3}$ \\ 1,2Department of Electrical Engineering, Annamalai University, Chidambaram, India \\ ${ }^{3}$ Department of Electronics and Instrumentation Engineering, RMK Engineering College, Chennai, India
}

\begin{tabular}{l}
\hline Article Info \\
\hline Article history: \\
Received Apr 17, 2021 \\
Revised Jul 24, 2021 \\
Accepted Aug 8, 2021 \\
\hline
\end{tabular}

\section{Keywords:}

DC micro-grid

GWO

High step up DC-DC converter

Hybrid energy source

SOFC

\begin{abstract}
The solid oxide fuel cell (SOFC) is used as secondary source in micro grid application. When the renewable sources are not able meet the load requirement, Battery energy back-up system is supposed to supply the energy to meet the demand. The SOFC come into action when the state of charge (SOC) of battery energy backup becomes too low. The SOFC parameters are assumed as constant during its operation but those operating parameters are not practically constant. The operating parameters vary widely which will influence the output voltage of SOFC. Hence an optimum power extracting controller is being implemented to ensure maximum power under dynamic operating condition. A high step up converter is designed to boost the output voltage of SOFC whose steady state analysis is studied in this work. The switches of high step up converter are triggered using optimum power controller using grey wolf based optimization algorithm. The proposed controller performance is compared with conventional particle swarm optimization based controller. The simulation is carried out using MATLAB/simulink and results discussed.
\end{abstract}

This is an open access article under the CC BY-SA license.

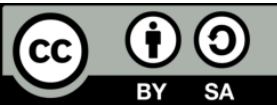

\section{Corresponding Author: \\ Sudhakiran Ponnuru \\ Research Scholar \\ Department of Electrical Engineering, Annamalai University \\ Chidambaram, Tamilnadu, India \\ Email : sudhakiranannamalaiphd17@gmail.com}

\section{INTRODUCTION}

Fuel cell technology is the most powerful for static power generation as well as power train applications because of its features like high efficiency, relatively low operating temperature, noise free and does not harness the environment. In this perspective, the researchers are looking forward to replace the conventional fossil fuels and add scope for overcoming the challenges faced by fuel cell technology. Among the types of fuel cell types, solid oxide fuel cell is best suited for static power generation and cogeneration applications due to its fascinating features like high efficient, moderate temperature and long life time. Though there are significant shortcoming will be shorted out to bring in market for commercially viable [1]-[5]. The researchers have been working towards it from the last decade and found fruitful results also. The remarkable studies related to grid connected SOFC are listed.

The DC micro-grid with hybrid source consist of PV system, wind turbine system and Solid oxide fuel cell was modeled and controlled under dynamic load condition and various environment condition [6]. In this method, indirect vector control was used to extract optimum power from wind turbine system and the maximum power extraction using perturb and observe method in solar PV system. The solid oxide fuel cell (SOFC) was used as secondary source when the power demand was not met by the PV and wind turbine system 
and no maximum power point tracking method was implemented for SOFC. A bidirectional six pulse PWM converter was used to manage the real and reactive power between DC grid and hybrid source. The result showed that there was good improvement in maintaining DC bus voltage and appreciable power quality improvement was also reported.

While interconnecting the renewable energy resources with grid, it was essential to use grid interactive converter (GIC) to manage the power requirement between grid and load including real and reactive power with intelligent controller to adjust the duty cycle according to substantial power requirement [7]. This work was dedicated to manage the real and reactive power requirement between grid and utility, current harmonics introduced due to non-linearity of the load and neutral current compensation in GIC. In this study, a multi focused objective function was formulated and it was solved by using adaptive fuzzy proportional integral controller which adjusts the duty cycle of the proposed grid interactive converter according to the system operating condition. The dynamic performance of the system was improved with the proposed control strategy under uncertainty incurred with good time domain parameters such as maximum peak overshoot and settling time. It was reported that the proposed control strategy could maintain good dynamic performance under all the dynamic operating condition with enhancement of power quality parameters meeting IEEE standards.

The proposed topology is shown in Figure 1. To manage the power sharing accurately in islanded DC micro-grid, feed forward neural network (FFNN) based droop control technique was proposed [8]-[9]. In this work, a hybrid sources consisting of solar PV system, wind energy turbine, battery energy storage system and SOFC were used to feed the grid and actual modeling of such sources were used instead of having ideal sources in distributed generation. The proposed control technique was used to maintain the voltage and frequency limit of the grid and real, reactive power requirement between DG units. The network was trained using data collected from one GG unit and checked to validate the efficacy of the proposed control technique; it was used in two distributed generation micro-grid system. It was also proved that the power sharing across the DG units done accurately compared to conventional droop technique with complex nature of the impedances in the line. It would also suit for micro-grid comprising of many number of DG units to restore the voltage and frequency in the grid.

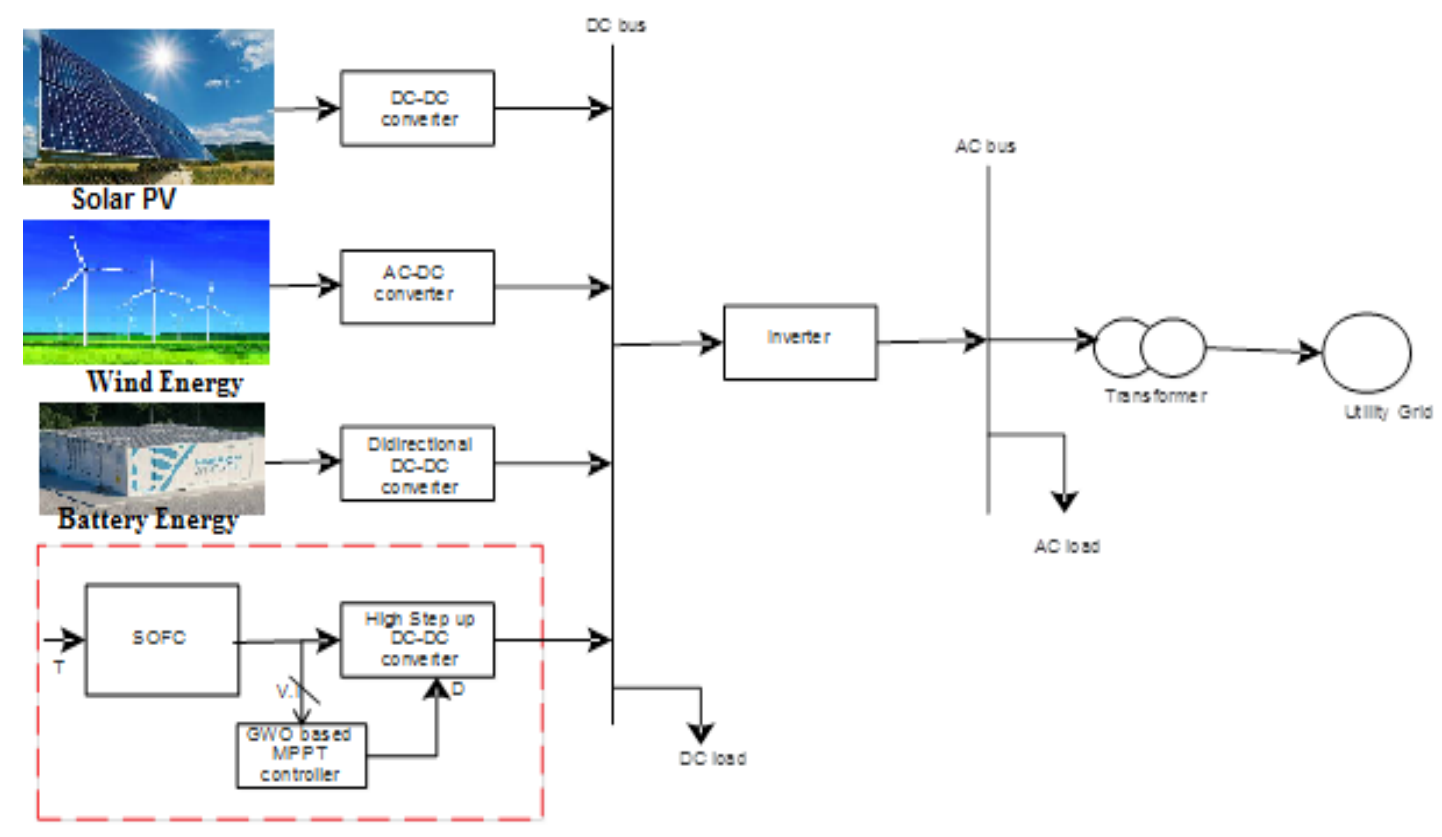

Figure 1. Hybrid energy source fed grid connected DC-DC converter

The autonomous operation of micro-grid fed from hybrid sources such as photovoltaic system, battery energy storage and SOFC was studied [10]-[12]. The mathematical models of all the connected sources were derived to analyze the performance. To restore the grid voltage, frequency and manage the power between grid and utility in the presence of load fluctuation and variation in PV output voltage, a fuzzy logic based intelligent controller was introduced. The main objective of battery energy storage system was to manage the real and reactive power demand of Photovoltaic system which could also maintain the DC link voltage as constant. 
The fuel cell was used as secondary source and supposed to be operated when state of charge (SOC) of BESS its limit. From the simulation study, it was evidenced that the proposed FLC controller outperforms the conventional PI controller.

The modeling and simulation of grid connected SOFC was carried out using PSCAD platform [9]. In the proposed study, there were three different case studies carried out to validate the performance. During the first case analysis, the fuel cell was connected without power regulation unit to supply constant and variable DC load. In the second case study, the fuel cell was supposed to supply variable three phase AC load. In the third case study, the fuel was connected to the grid to meet the load demand. It was also reported that the power regulating unit was designed to condition the fuel cell output voltage. From the simulation results, it was revealed that the SOFC power production was yielded better results to supply the various load demands and exhibited good performance with grid connected system.

\section{MODELING OF SOFC}

The structure of SOFC is shown in Figure 2. The electrolyte is taken in the form of solid material like zirconium stabilized with Yttria and hence the fuel cell is name so. The typical operating temperature of SOFC is around $800^{\circ} \mathrm{C}-1000^{\circ} \mathrm{C}$. At this temperature, the fuel is supplied at cathode to reduce and forms the hydrogen ions which are accelerated towards the anode [1]-[5]. The hydrogen ions are carried through solid electrolyte. The hydrogen ion reaches the anode and oxidization takes places. The hot water is obtained as byproduct along with carbon dioxide [13]-[18]. During the entire process, high temperature issue is addressed. Hence it is necessary to accommodate thermally stable, hard and rigid materials to withstand the high operating temperature [19]-[22].

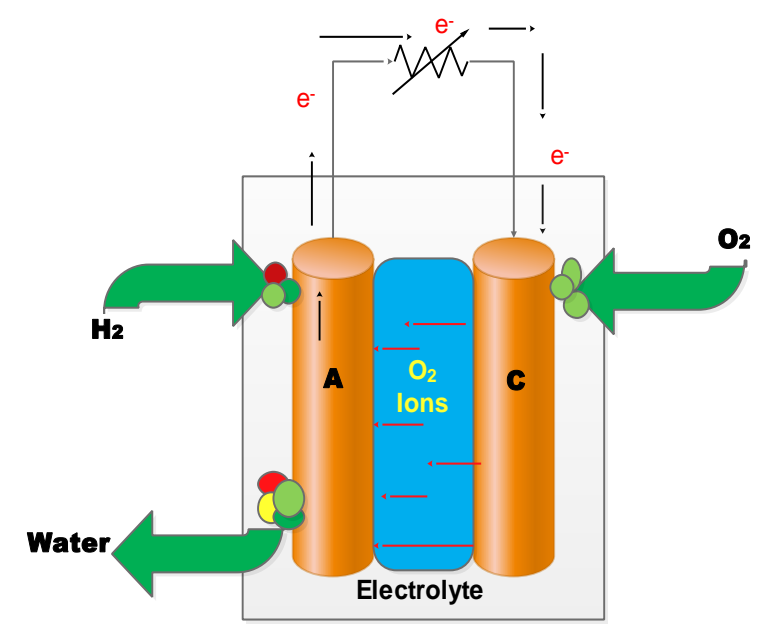

Figure 2. Structure of solid oxide fuel cell

The output voltage across SOFC output terminals is given by,

$$
V_{\text {SOFC }}=E_{\text {nernst }}-V_{C}-V_{Q}-V_{R}
$$

$E_{\text {nernst- }}$ Nernst voltage, $\mathrm{V}_{\mathrm{c}}$-concentration voltage drop, $\mathrm{V}_{\mathrm{a}}$-activation voltage drop, $\mathrm{V}_{\mathrm{R}}$-ohmic voltage drop. Nerst voltage can be written as,

$$
E_{\text {nernst }}=E_{\text {gtd }}+\left(\frac{R T}{2 F} \ln \frac{P_{\mathrm{Hz}_{2} P_{O_{2}}^{1 / 2}}}{P_{\mathrm{HZ}_{2} \mathrm{O}}}\right)
$$

$\mathrm{E}_{\text {std- }}$ Standard voltage(typically $1.1 \mathrm{~V}$ at standard voltage), R-universal gas constant, T-cell operating temperature, F-Faraday constant, $\mathrm{P}_{\mathrm{H} 2}, \mathrm{P}_{\mathrm{O} 2}, \mathrm{P}_{\mathrm{H} 2 \mathrm{O}^{-}}$Hydrogen, Oxygen, water partial pressure respectively.

$$
P_{H_{2}}=\frac{\left[{ }_{k} k_{2}\right\rfloor}{\left[1+s \pi_{H_{2}}\right]}\left(q H_{2}^{f}-2 K I_{f e}\right)
$$




$$
\begin{aligned}
& P_{O_{2}}=\frac{\llbracket 1 h_{k O_{2}} \rrbracket}{\left.\llbracket 1+\Delta \tau_{O_{2}}\right]}\left(\frac{1}{H_{l_{0}}} q H_{2}^{f}-K l_{f o}\right) \\
& P_{\mathrm{H}_{2 \mathrm{O}}}=\frac{\left.\llbracket 1_{\mathrm{kH}} \mathrm{O}\right\rfloor}{\left[1+\Delta \mathrm{T}_{\mathrm{H}_{2} \mathrm{D}}\right\rfloor}\left(2 \mathrm{KI}_{\mathrm{fo}}\right) \\
& I_{f e}=I_{0}\left(e^{\left(\frac{2 a r a V_{0}}{R T}\right)}\right)
\end{aligned}
$$

$\mathrm{kH}_{2}, \mathrm{kO}_{2}, \mathrm{kH}_{2} \mathrm{O}$ - valve molar constant for hydrogen, oxygen and water respectively, $\mathrm{qH}_{2}$-flow rate for hydrogen $\tau_{\mathrm{H}_{2},}, \tau_{\mathrm{O}_{2}}, \tau_{\mathrm{H}_{2} \mathrm{O}}$-response time for hydrogen, oxygen and water respectively, $\mathrm{I}_{\mathrm{O}}$-exchange current, $\mathrm{K}$ is constant (expressed in k.mol/S.A).

From the mathematical modeling of SOFC, it is clearly inferred that the terminal voltage of fuel cell is quite complex since a lot of parameters influencing it. Among all the influencing parameters, the cell operating temperature, hydrogen partial pressure and oxygen partial pressure are the most significant as per literature study [20]-[21]. Hence these three parameters are taken in this study to analyze the performance of grid connected SOFC under dynamic operating condition.

\subsection{High step up converter}

The proposed converter consist of two power semiconductor switches $\left(\mathrm{S}_{1}, \mathrm{~S}_{2}\right)$ and two inductors $\left(\mathrm{L}_{1}, \mathrm{~L}_{2}\right)$ are connected in two legs. Both these switches are triggered and turned off simultaneously and it is enough to generate one switching pulse as like conventional boost converter from proposed MPPT controller. The output capacitors $\left(\mathrm{O} / \mathrm{P} \mathrm{C}_{1}, \mathrm{O} / \mathrm{P} \mathrm{C}_{2}\right)$ are used to share the output voltage equally without aid of an external arrangement. Apart from two output capacitor, one more capacitor $\mathrm{C}$ is connected across the switch $\mathrm{S}_{1}$ and diode $\mathrm{D}_{1}$ which stores the energy and acting like switched capacitor. The circuit components and its arrangement is shown in Figure 3.

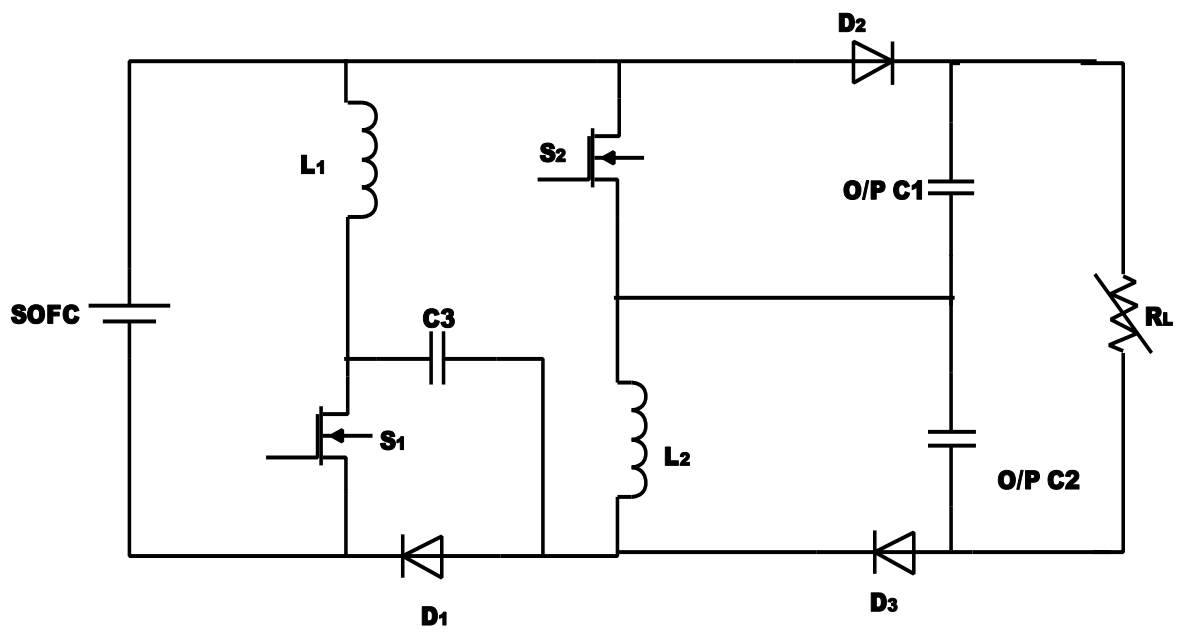

Figure 3. High step up boost converter

Mode I:

During mode 1 operation, both the switches remain $\mathrm{ON}$ condition and diode $\mathrm{D}_{1}, \mathrm{D}_{2}$ are in $\mathrm{OFF}$ condition. To have equal voltage stress across the switches, there are two output capacitors connected across the load. The current direction during this mode is indicated in Figure 4 (a).

Mode II

In this mode both the switches are turned off and diode D3 is reversing biased and it losses conduction. However the load current will not reach zero because of the output capacitors. The corresponding current direction of this mode is shown in Figure 4 (b). The expected key waveform of the proposed topology is shown in Figure 4. 


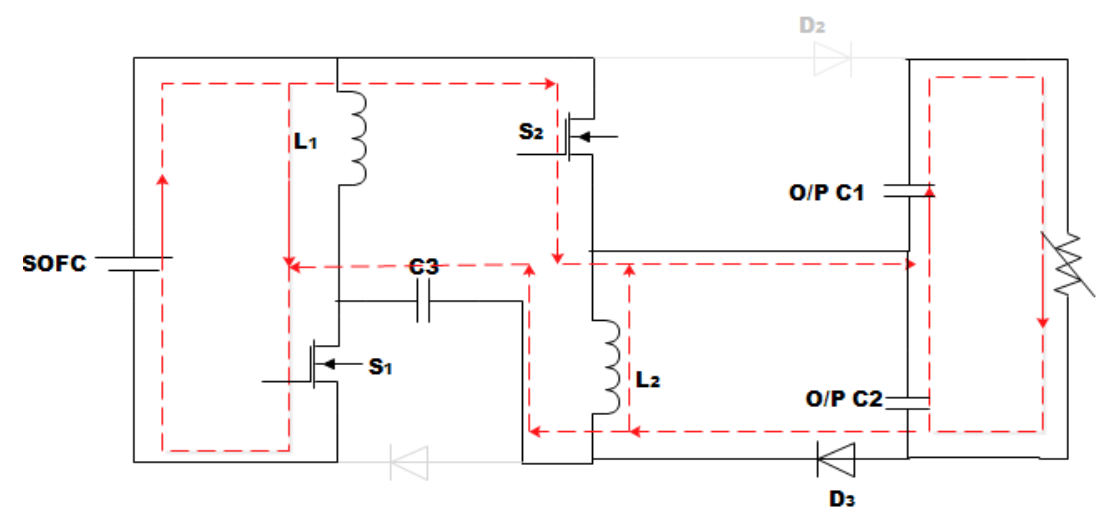

Figure 4 (a). Mode I operation

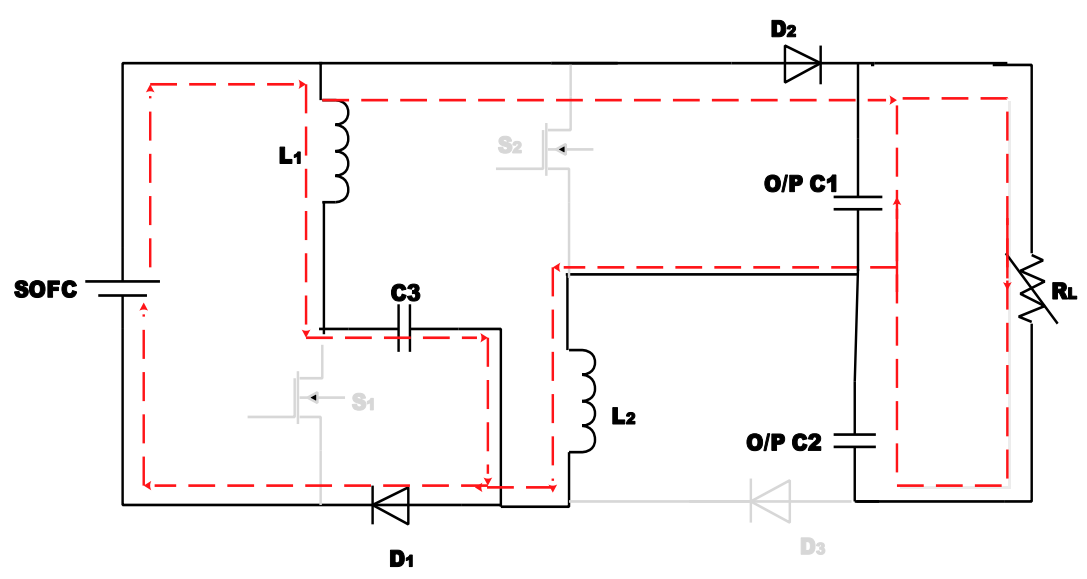

Figure 4 (b). Mode II operation

Figure 4. Mode of operation

\subsection{Voltage gain}

Voltage across the capacitor $\mathrm{C}$ can be written as [23],

$$
V_{C}=\frac{1}{1-8} V_{i n}
$$

the voltage-second balance equation can be written as [24],

$$
V_{L 1}^{I} T^{\text {on }}=V_{L 1}^{I I} T^{\text {off }}
$$

From the mode 1 operation, it is inferred that $\mathrm{V}_{\mathrm{L} 1}=\mathrm{V}_{\text {in }}$, and voltage across the output capacitor can be written as,

$$
V_{\mathrm{Co2}}=\frac{1}{(1-\delta)^{2}} V_{\mathrm{in}}
$$

the voltage across the output capacitor 2 can be written as,

$$
\begin{aligned}
& V_{c 02}=V_{i n}+V_{c} \\
& V_{c 02}=V_{i n}+\frac{1}{1-6} V_{i n}
\end{aligned}
$$




$$
V_{c o 2}=\frac{2-8}{1-8} V_{\mathrm{in}}
$$

total output voltage can be written as,

$$
V_{0}=V_{C 01}+V_{C 02}
$$

by substituting the (3) and (6) in (7), we get,

$$
M=\frac{\left(d^{2}-3 \delta+a\right)}{\left([1-\delta)^{2}\right.}
$$

$\delta$-duty cycle, M-over all gain of the proposed converter, Vo-output voltage, $\mathrm{V}_{\mathrm{Col}}$-voltage across the

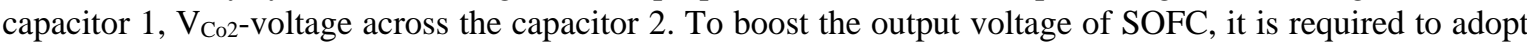
suitable DC-DC converter as regulating unit [25].

\subsection{Grey wolf optimization}

The researchers have started to solve engineering related multi objective optimization problems using Meta-heuristic algorithms because it is taking less time and computational effort needed also less. Among the indirect search algorithms, GWO is one which mimics the hunting behavior of grey wolf [18]. There are four categories of grey wolves involved in its leadership hierarchy. They are listed; i] alphas (its responsibility is to organize its group and commend to perform); ii] betas (it is supporting the alphas in decision making and give suggestion to alphas); iii] omegas (it is scapegoat of its group and can be considered as soldier); iv] Deltas (pioneer of this group and supposed to help the alphas and betas whenever crisis arises); while chasing the prey, the grey wolves start surrounds the prey and fight against it. Eventually the prey will be hunted by group and shared among the group according to their hierarchy. The hunting behavior can be mathematically expressed,

$$
\begin{aligned}
& \vec{d}=\left|\vec{c} \cdot \overrightarrow{X_{\text {position }}}(t)-\vec{X}(t)\right| \\
& \vec{X}(t+1)=\overrightarrow{X_{\text {postion }}}(t)-\vec{d} \vec{d}
\end{aligned}
$$

where $\overrightarrow{X_{\text {portron }}}(t)$ - position vector of the hunt, $\vec{X}(t)$ - position of wolf, vectors, $\vec{a} \vec{c}-$ represents the coefficient vectors.

$$
\begin{aligned}
& \vec{a}=2 \varepsilon \overrightarrow{r_{0}}-\zeta \\
& \vec{c}=2 \vec{r}_{j}
\end{aligned}
$$

Where $\zeta$-is decreasing from 2 to 0 linearly in the interval of iteration, $\vec{r}_{1}, \vec{r}_{j}-$ random vectors in the interval of $[0,1]$. The best solution is given by alpha, beta and gammas while omegas are expected to update its vector position to give best solution. The same can be mathematically expressed,

$$
\begin{aligned}
& \overrightarrow{D_{\alpha}}=\left|\overrightarrow{c_{\underline{I}}} \overrightarrow{X_{\alpha}}-\vec{x}\right| \\
& \overrightarrow{D_{\beta}}=\left|\overrightarrow{c_{j}} \overrightarrow{X_{\beta}}-\vec{X}\right| \\
& \overrightarrow{D_{\hat{b}}}=\left|\overrightarrow{c_{k}} \overrightarrow{X_{\hat{b}}}-\vec{X}\right| \\
& \overrightarrow{R_{1}}=\overrightarrow{X_{\alpha}}-\overrightarrow{a_{1}} \overrightarrow{D_{\alpha}} \\
& \overrightarrow{R_{2}}=\overrightarrow{X_{\delta}}-\overrightarrow{a_{k}} \overrightarrow{D_{\hat{\sigma}}} \\
& \vec{X}(t+1)=\frac{\left.\sqrt{X_{1}}+\overrightarrow{X_{2}}+\overrightarrow{X_{2}}\right]}{3}
\end{aligned}
$$


the wolves are waiting until there is no movement in the prey. It starts attacking the prey immediately as instructed by its superior in the hierarchy. Hence the value of $\zeta$ is decreasing from its upper value to null linearly and wait for $|\vec{a}|$ value becomes less than one. If its value is less than one, it starts attacking the hunt; otherwise it is instructed to search until desired value is achieved.

\section{RESULTS AND DISCUSSION}

To simulate the performance of proposed GWO controller under dynamic temperature condition, a 20W SOFC is considered whose operating parameters are listed in Table 1 . The operating temperature is considered to be a variable parameter which is varied: $1273 \mathrm{~K}$ for $(0-1 \mathrm{sec}), 1243 \mathrm{~K}$ for $(1-2 \mathrm{sec})$ and $1303 \mathrm{~K}$ for $(2-3 \mathrm{sec})$.It is not sufficient enough to meet the load or grid voltage directly from SOFC from output. Hence it is inevitable to connect a step up converter to boost the voltage and regulate the power according to the operating temperature. Hence a high step up boost converter is designed using the parameters listed in Table 2. The input voltage and current for the high step up converter at normal operating temperature is $42 \mathrm{~V}$ and $0.5 \mathrm{~A}$ respectively which is shown in Figures 5 to 6 .

Table 1. Fuel cell parameters

\begin{tabular}{ccc}
\hline S.no & Parameter & Value \\
\hline 1 & Absolute temperature-(K) & $1273,1243,1303$ \\
2 & Universal gas constant-R $(\mathrm{C} / \mathrm{kmol})$ & 8314 \\
3 & Standard potential-(V) & 1.1 \\
4 & Number of cells connected in stack & 44 \\
5 & Optimal fuel utilization & $85 \%$ \\
6 & Ratio of hydrogen to oxygen & 1.145 \\
7 & Electrical response time $-(\mathrm{sec})$ & 0.8 \\
8 & Response time for hydrogen-(sec) & 26.1 \\
\hline
\end{tabular}

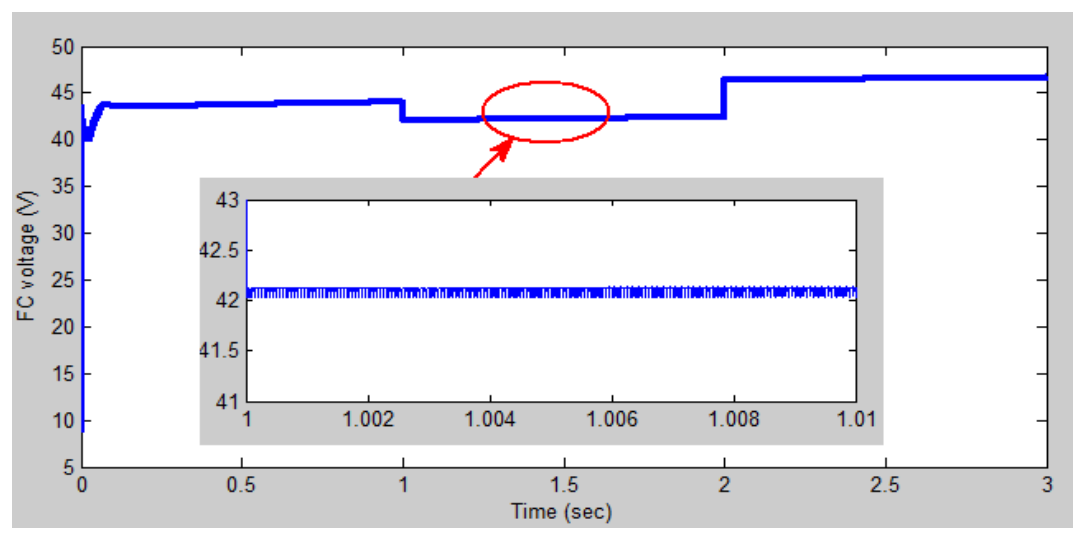

Figure 5. Voltage waveform under dynamic temperature condition

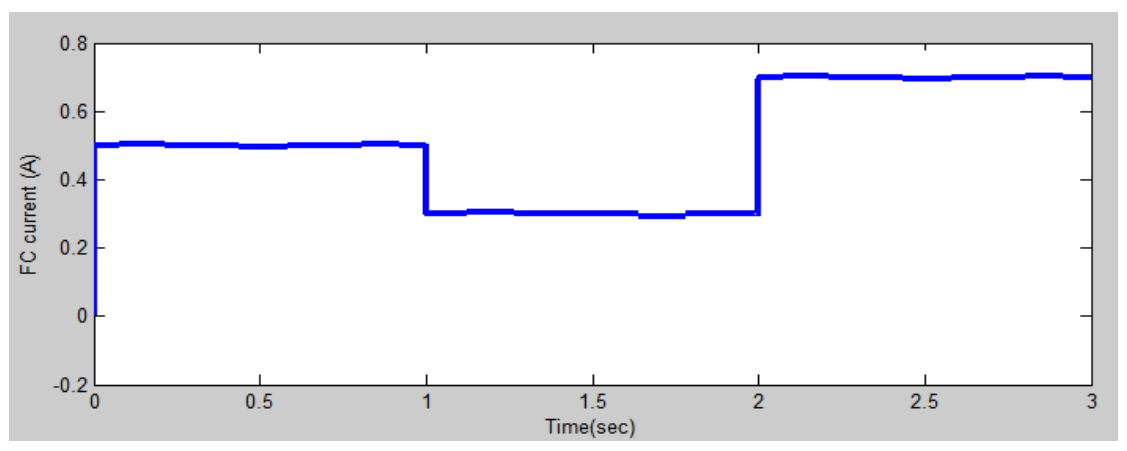

Figure 6. Current waveform under dynamic temperature condition 
The output voltage and current have the large amount of ripples. The same voltage is fed to high step up converter and it is boosted to $400 \mathrm{~V}$ at duty cycle of 0.61 which is approximately ten times the input voltage. The DC link voltage, current and power from Step up converter is shown in Figures 7 to 8 in which the ripple content has been reduced considerably under dynamic operating temperature.

Table 2. High step up converter parameters

\begin{tabular}{ccc} 
S.no & Parameter & Value \\
\hline 1 & Input voltage at 1273K & $40 \mathrm{~V}$ \\
2 & Output voltage & $400 \mathrm{~V}$ \\
3 & Operating frequency & $10 \mathrm{kHz}$ \\
4 & Capacitors (each) & $2700 \mu \mathrm{F}$ \\
5 & Inductors (each) & $3 \mathrm{mH}$ \\
6 & MOSFET & Ideal \\
7 & Diodes & Ideal \\
\hline
\end{tabular}

To extract the maximum power from SOFC, GWO controller is adopted. To reduce the peak overshoot at the time of starting, the duty cycle is also reduced and it is traced the maximum power during varying temperature condition also as shown in Figure 7.

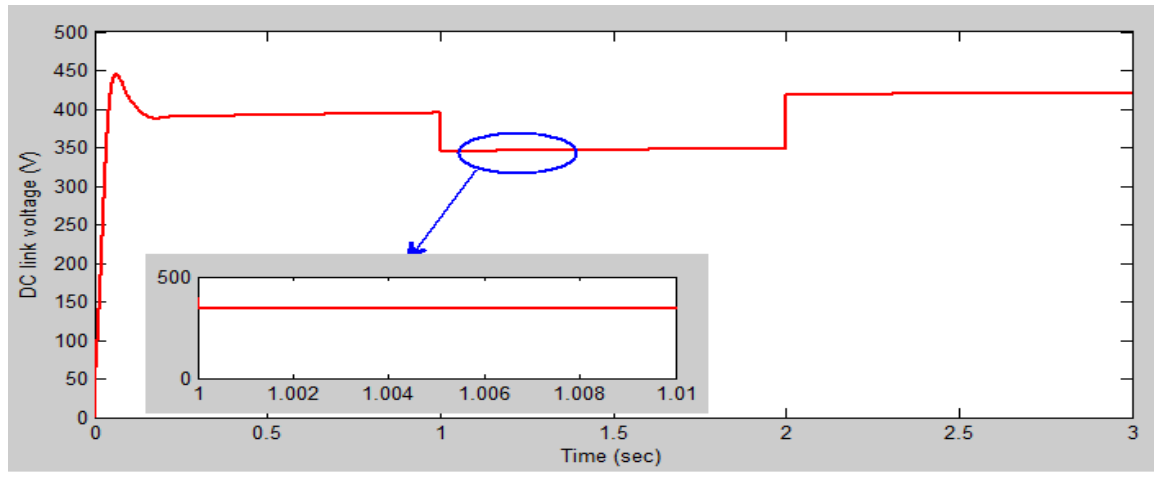

Figure 7. DC link voltage under dynamic temperature condition

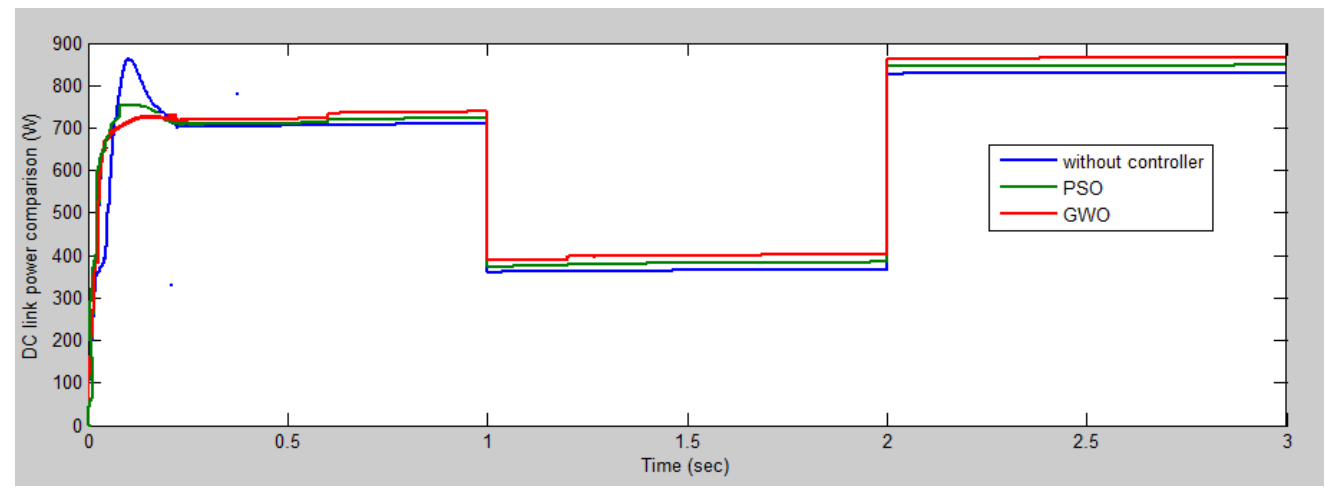

Figure 8. DC link power comparisons

To check the efficacy of the proposed GWO controller, the maximum power traced by conventional PSO controller and GWO controller is compared to the output power without controller as shown in Figure 8. It is clearly inferred that the power traced by GWO controller yielded the better results compared to conventional PSO controller. The output voltage ripple was reduced to $5 \%$ than the output voltage obtained without controller. The reduction of peak overshoot by the GWO controller is $21 \%$ and conventional PSO controller is $7 \%$. The settling time for GWO controller is $0.2 \mathrm{sec}$ and for conventional PSO controller is 0.23 sec. 


\section{CONCLUSION}

A high step up converter was designed to boost the output voltage of SOFC and regulate the output voltage during dynamic operating condition and its detailed analysis discussed in detail. As the operating temperature had major impact on output voltage of SOFC, it was considered to be dynamic variable. The grey wolf optimization algorithm was used in MPPT controller to generate the switching pulses to high step up converter under dynamic operating temperature. The performance the proposed GWO controller outperformed the conventional PSO controller and the following observations made. 1) The GWO controller could extract $5 \%$ more power than conventional PSO controller and reduce the output voltage ripple by 7\%. 2) The peak overshoot of DC link power was reduced by $21 \%$. 3) The time to reach and settle down to steady state output power was reduced to 0.2 second.

\section{REFERENCES}

[1] Larminie, James, Andrew Dicks, and Maurice S. McDonald, "Fuel cell systems explained," vol. 2. Chichester, UK: J. Wiley, 2003.

[2] Bove, Roberto, and Stefano Ubertini, eds, "Modeling solid oxide fuel cells: methods, procedures and techniques," Springer Science \& Business Media, 2008, doi: 10.1007/978-1-4020-6995-6.

[3] Brandon, Nigel et al., "Solid oxide fuel cells: from materials to system modelling," Royal society of chemistry, 2013, doi: 10.1039/9781849737777.

[4] Andersson, Martin, Jinliang Yuan, and Bengt Sundén, "SOFC modeling considering hydrogen and carbon monoxide as electrochemical reactants," Journal of Power Sources, vol. 232, pp. 42-54, 2013, doi: 10.1016/j.jpowsour.2012.12.122.

[5] Jarek Milewski, Konrad Świrski, Massimo Santarelli and Pierluigi Leone, "Advanced methods of solid oxide fuel cell modelling," Springer Science \& Business Media, 2011, doi: 10.1007/978-0-85729-262-9.

[6] Ahmad Eid, "Utility Integration of PV-wind-fuel cell hybrid distributed generation under variable load demands," International journal of Electrical Power and Energy Systems, vol. 62, pp. 689-699, 2014, doi: 10.1016/j.ijepes.2014.05.020.

[7] Thangavel, Vigneysh and Kumarappan, N, "Grid interconnection of renewable energy sources using multifunctional grid-interactive converters: A fuzzy logic based approach,” Electric Power Systems Research, vol. 151, pp. 359-368, 2017, doi: 10.1016/j.epsr.2017.06.010.

[8] Thangavel, Vigneysh and Kumarappan, N, "Artificial Neural Network Based Droop-Control Technique for Accurate Power Sharing in an Islanded Microgrid," International Journal of Computational Intelligence Systems, vol. 9, no. 5, pp. 827-838, 2016, doi: 10.1080/18756891.2016.1237183.

[9] T. Vigneysh and N. Kumarappan, "Autonomous operation and control of photovoltaic/solid oxide fuel cell/battery energy storage based microgrid using fuzzy logic controller," International Journal of Hydrogen Energy, vol. 41, no. 3, pp. 1877-1891, 2016, doi: 10.1016/j.ijhydene.2015.11.022.

[10] Fedakar, Seyfullah, S. E. R. K. A. N. Bahceci, and T. Yalcinoz, "Modeling and simulation of grid connected solid oxide fuel cell using PSCAD," Journal of Renewable and Sustainable Energy, vol. 6, no. 5, p. 053118, 2014, doi: 10.1063/1.4897936.

[11] Chanasut, Nawapan, and Suttichai Premrudeepreechacharn, "Maximum power control of grid-connected solid oxide fuel cell system using adaptive fuzzy logic controller," 2008 IEEE Industry Applications Society Annual Meeting. IEEE, 2008, doi: 10.1109/08IAS.2008.278.

[12] Zhou, Niancheng,"Modelling and control of solid oxide fuel cell generation system in microgrid," Journal of Electrical Engineering, vol. 68, no. 6, p. 405, 2017, doi: 10.1515/jee-2017-0075.

[13] Li, Yonghui, Qiuwei Wu, and Haiyu Zhu, "Hierarchical load tracking control of a grid-connected solid oxide fuel cell for maximum electrical efficiency operation," Energies, vol. 8, no. 3, pp. 1896-1916, 2015, doi: 10.3390/en8031896.

[14] Irshad, Muneeb et al., "A brief description of high temperature solid oxide fuel cell's operation, materials, design, fabrication technologies and performance," Applied Sciences, vol. 6, no. 3, p. 75, 2016, doi: 10.3390/app6030075.

[15] Wu, Zhen et al., "Dynamic modeling and operation strategy of an NG-fueled SOFC-WGS-TSA-PEMFC hybrid energy conversion system for fuel cell vehicle by using MATLAB/SIMULINK," Energy, vol. 175, pp. 567-579, 2019, doi: 10.1016/j.energy.2019.03.119.

[16] Aram Khodamoradi, Guangyuan Liu, Paolo Mattavelli, Tuomas Messo, Hossein Abedini, "PRBS-based loop gain identification and output impedance shaping in DC microgrid power converters," Mathematics and Computers in Simulation, vol. 183, no. 7, pp. 129-141, 2021, doi: 10.1016/j.matcom.2020.04.017.

[17] L. Barelli, G. Bidini and A. Ottaviano, "Part load operation of a SOFC/GT hybrid system: dynamic analysis," Applied energy, vol. 110, pp. 173-189, 2013, doi: 10.1016/j.apenergy.2013.04.011.

[18] A. Naserbegi, M. Aghaie, and A. Zolfaghari, "Implementation of Grey Wolf Optimization (GWO) algorithm to multiobjective loading pattern optimization of a PWR reactor," Annals of Nuclear Energy, vol. 148, p. 107703, 2020, doi: 10.1016/j.anucene.2020.107703.

[19] T. V. V. S. Lakshmi, P. Geethanjali and Prasad S. Krishna, "Mathematical modelling of solid oxide fuel cell using Matlab/Simulink," 2013 Annual International Conference on Emerging Research Areas and 2013 International Conference on Microelectronics, Communications and Renewable Energy, IEEE, 2013, doi: 10.1109/AICERAICMiCR.2013.6576016. 
[20] Vigneysh Thangavel and Kumarappan Narayanan, "An Adaptive Fuzzy Pi Controller for Performance Enhancement of Microgrid Power Quality Conditioner," Control and Intelligent Systems, vol. 45, no. 4, 2017, doi: 10.2316/journal.201.2017.4.201-2825.

[21] Mi, Yang et al., "A Power Sharing Strategy for Islanded DC Microgrid with Unmatched Line Impedance and Local Load," Electric Power Systems Research, vol. 192, p. 106983, 2021, doi: 10.1016/j.epsr.2020.106983.

[22] K. Jyotheeswara Reddy and N. Sudhakar, ”A new RBFN based MPPT controller for grid-connected PEMFC system with high step-up three-phase IBC, "International Journal of Hydrogen Energy, vol. 43, no. 37, 2018, Hydrogen Energy Publications LLC. Published by Elsevier Ltd, doi: 10.1016/j.ijhydene.2018.07.177.

[23] P. Wang, L. Zhou, Y. Zhang, J. Li, and M. Sumner, "Input-parallel Output-series DC-DC Boost Converter with a wide input voltage range, for fuel cell vehicles," IEEE Trans. Veh. Technol., vol. 66, no. 9, pp. 7771-7781, 2017, doi: 10.1109/TVT.2017.2688324.

[24] M. Lakshmi and S. Hemamalini, "Nonisolated high gain DC-DC converter for DC microgrids," IEEE Transactions on Industrial Electronics, vol. 65, no. 2, pp. 1205-1212, 2017, doi: 10.1109/TIE.2017.2733463.

[25] G. Indira Kishore and Ramesh Kumar Tripathi, "High Gain Single Switch DC-DC Converter Based on Switched Capacitor Cells," Journal of Circuits, Systems and Computers, vol. 29, no. 12, p. 2050188, 2020, doi: $10.1142 / \mathrm{S} 0218126620501881$.

\section{BIOGRAPHIES OF AUTHORS}

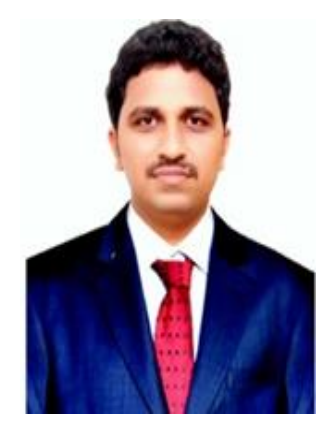

Mr. Sudhakiran Ponnuru, He is as Research Scholar, Department of Electrical Engineering, FEAT, AnnamalaiUniversity, Chidambaram, and Tamilnadu, India. He has received his B.Tech Degree in Electrical and Electronics Engineering in 2008, JNTU, Hyderabad, India. ,M.Tech VLSI DESIGN in 2010, Sathyabama University, Chennai, Tamil Nadu, India. And M.Tech Power Electronics in 2017 JNTU, Anatapur, Andhra Pradesh, India. His area of interest includes Renewable Energy Technologies, Power System and Micro Grids.

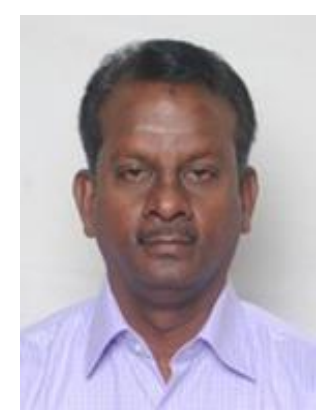

Prof. Ashok kumar R, is working as professor in the Department of Electrical Engineering, Annamalai University, Annamalai nagar, Tamilnadu, India. He completed M.E (Power system engineering) in the year 1999 and Ph.D in Electrical Engineering in 2009, from Annamalai University. He joined Annamalai University in the year 1994 as lecturer and then elevated to the level of professor. His research interest includes Power systems operation and control, Radial distributed systems, Deregulated power systems and Renewable energy. He is a member of ISTE and other Technical bodies.

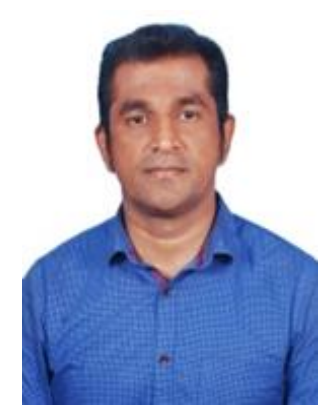

Prof. N. M. Jothi Swaroopan, He is working as Professor in the Department of Electronics and Instrumentation Engineering, in RMK Engineering College, Chennai, Tamil Nadu, India. He has received his B.E degree in Electrical and Electronics Engineering in 1997, M.E.in Power systems engineering in 2005 College of Engineering, Guindy, Tamil Nadu, India, and Ph.D. in Power systems Economics Dispatch. In 2011 College of Engineering, Guindy, Tamil Nadu, India. From His areas of interest include Renewable energy technologies, Power System and Power Electronics. 